\title{
PERANCANGAN KURSI TANGGA MENGGUNAKAN METODE QUALITY FUNCTION DEPLOYMENT
}

\author{
Antonius Sugianto $^{1}$, Ignatius Ngesti Yuwono ${ }^{2}$, Kristianus Satriawan ${ }^{3}$ \\ ${ }^{1}$ Akademi Teknik PIKA Semarang \\ Email: ugik_pika@yahoo.co.id \\ ${ }^{2}$ Akademi Teknik PIKA Semarang \\ Email:ngesti.yuwono@gmail.com \\ ${ }^{3}$ Akademi Teknik PIKA Semarang \\ Email: satriawan_309@yahoo.com
}

Masuk: 28-05-2020, revisi: 29-08-2020, diterima untuk diterbitkan: 03-09-2020

\begin{abstract}
ABSTRAK
Keterbatasan ruang dalam melaksanakan aktivitas menuntut tersedianya furnitur yang memiliki multifungsi. Tujuan penelitian ini merancang Kursi Tangga yang memiliki multi fungsi. Metode yang digunakan adalah Quality Function Deployment. Metode Quality Function Deployment digunakan untuk mendapatkan variabel produk yang diinginkan oleh sebagian besar calon pemakai sehingga diharapkan hasil perancangan dapat memenuhi keinginan konsumen. Variabel produk yang ada merupakan penjabaran dari aspek utama dalam merancang sebuah produk yaitu fungsi, bentuk, konstruksi dan bahan. Aspek utama dalam perancangan ini harus diperhatikan agar menghasilkan rancangan produk yang memenuhi kriteria dalam teknik mendesain furniture yang benar. Pemahaman akan pentingnya ergonomi dan antropometri sangat diperlukan agar tujuan utama perancangan produk yang sesuai dengan keinginan konsumen dapat terpenuhi. Kenyamanan dan keamanan menjadi sesuatu parameter yang harus dipenuhi. Kesesuaian ukuran furniture dengan pengguna harus diperhatikan agar kenyamanan dalam pemakaian dapat terpenuhi. Aplikasi metode Quality Function Deployment merekomendasikan bahwa pengembangan produk Kursi Tangga harus memperhatikan variabel kebutuhan konsumen yang memiliki bobot tinggi yaitu menggunakan bahan baku yang kuat, menggunakan bahan baku yang awet, menggunakan konstruksi maksimal 2 jenis, sistem perakitan mati.
\end{abstract}

Kata kunci: kursi tangga; multi fungsi; perancangan; quality function deployment

\begin{abstract}
Limited space in carrying out activities demanded the availability of furniture that has multifunctional. The purpose of this research is to design a multi-functional Stair Chair. The method used is Quality Function Deployment. The Quality Function Deployment method is used to obtain the product variables desired by most prospective users so that expected design results can fulfill the consumer's wishes. Existing product variables are the description of the main aspects of designing a product i.e. function, shape, construction and material. The main aspects of this design should be considered in order to produce a product design that meets the criteria in designing the correct furniture techniques. The understanding of the importance of ergonomics and anthropometry is indispensable for the main purpose of product design that is appropriate to the wishes of consumers can be fulfilled. Comfort and security become something the parameters must be met. Suitability of the size of furniture with users should be noticed for comfort in use can be fulfilled. Application method of Quality Function Deployment recommends that the development of stair seat products should be aware of the variable needs of consumers who have high weight, namely using strong raw materials, using raw materials that are durable, Using a maximum construction of 2 types, the system of fix assembly.
\end{abstract}

Keywords: design; ladder chair; multi function; quality function deployment

\section{PENDAHULUAN}

Penggunaan furnitur multifungsi mulai mengubah gaya hidup sebagian masyarakat di kota-kota besar khususnya negara maju seperti Jepang, Amerika, Jerman hingga akhirnya juga merambah negara berkembang seperti Indonesia. Beberapa unsur yang menjadikan furniture tersebut multifungsi adalah mudah untuk dipindahkan (mobile), mampu berubah bentuk (transformable), bervariasi dan menggunakan bahan yang kuat (Hartanto, 2014). Furnitur memiliki keuntungan apabila dapat diperbesar, dilipat, digunakan untuk beberapa fungsi berbeda dan memiliki roda agar mudah dipindahkan (Akmal, 2011). 
Quality Function Deployment, atau lebih sering disebut $Q F D$, adalah suatu konsep perancangan produk yang lahir di Jepang di tahun 1960-an. Pada saat itu industri di Jepang mulai meninggalkan kebiasaan meniru produk-produk yang sudah ada, dan beralih menciptakan produk-produk orisinal. Sejak itu QFD mulai digunakan secara luas dan terbukti efektif, mulai dari industri otomotif, pesawat terbang, sampai ke perusahaan jasa (Permata, 2017). Beberapa tahun terakhir QFD makin populer di dunia akademis dan banyak digunakan untuk perancangan bahan ajar suatu matakuliah di universitas sampai ke perancangan kurikulum dan cara pengajaran untuk jurusan teknik industri di Indonesia (Ginting, 2010). Aspek-aspek manusia dalam lingkungan kerjanya yang ditinjau secara anatomi, fisiologi, psikologi, engineering, manajemen, dan desain atau perancangan. Ergonomi menjadi suatu aplikasi informasi ilmiah tentang manusia untuk permasalahan desain (Nurmianto, 1998). Antropometri adalah pengetahuan yang menyangkut pengukuran dimensi tubuh manusia dan karakteristik khusus lain dari tubuh yang relevan dengan perancangan alat-alat/benda-benda yang digunakan manusia (Pheasant, 1998). Penelitian yang dilakukan adalah mendapatkan hasil perancangan kursi tangga baru yang lebih nyaman terkait dengan desain kursi tangga yang lebih ergonomis menyesuaikan dengan keinginan pemakai. (Wiliaury, 2015). Ukuran ergonomis terkait dengan ukuran sudut kemiringan, ketinggian anak tangga dan lebar anak tangga.

\section{METODE PENELITIAN}

Metode penelitian menggunakan Quality Function Deployment (QFD) dimana informasi yang berkaitan dengan perancangan produk diperoleh dari calon pemakai. Perancangan Kursi Tangga memuat uraian mengenai analisa dari penerapan Quality Function Deployment (QFD) yang meliputi analisa planning matrix, evaluasi tingkat kepuasan konsumen, penentuan prioritas dari kepentingan teknik yang akan dikembangkan agar dapat memenuhi kebutuhan calon pemakai (Prabowo, 2016). Penyusunan kuesioner merupakan hal yang pokok untuk pengumpulan data. Tujuan pokok penyusunan kuesioner adalah untuk memperoleh informasi yang relevan dengan tujuan survei dan untuk memperoleh informasi dengan validitas dan reliabilitas. Setelah mengidentifikasi kebutuhan konsumen, maka dilakukan penyusunan kuesioner dari hasil wawancara dan penentuan responden untuk menjawab kuesioner. Penyusunan kuesioner dilakukan melalui dua tahap, yaitu tahap awal dan tahap akhir. Tahap awal merupakan tahap penyusunan kuesioner berdasarkan kebutuhan konsumen yang ada. Teknik pengumpulan data dengan memberikan sejumlah pertanyaan kepada narasumber. Sedangkan daftar pertanyaan yang diberikan adalah dalam bentuk angket dengan pilihan jawaban yang tiap poin angka mempunyai beberapa tingkat arti kepentingan yang berbeda. (Hamdani, 2015)

Pengelompokan data ke dalam beberapa kategori yang menunjukkan banyaknya data dalam setiap kategori. Setiap data tidak dapat dimasukkan ke dalam dua atau lebih kategori. Dari pengertian-pengertian di atas dapat disimpulkan bahwa distribusi frekuensi mencakup penyajian data, pengelompokan data ke dalam suatu daftar atau tabel. (Yuliarty, 2015)

\section{HASIL DAN PEMBAHASAN}

Metode QFD dalam penelitian digunakan untuk mendapatkan desain produk baru yang sesuai dengan keinginan pemakai. Penyebaran kuisioner dilakukan untuk mendapatkan informasi terkait dengan kebutuhan dalam perancangan kursi tangga, Proses identifikasi dan perumusan masalah dilakukan terhadap Kursi Tangga yang terdapat di Akademi Teknik PIKA Semarang. Gambar 1 menunjukkan Kursi Tangga tersebut dan Gambar 2 menunjukkan gambar tampak dan ukuran Kursi Tangga. Penggunaan Kursi Tangga tidak berbeda dengan kursi pada umumnya dan memiliki ukuran menurut norma standart yang ada. Pada saat Kursi Tangga akan difungsikan sebagai tangga naik, proses cukup sederhana yaitu dengan memutar sandaran punggung sebesar 
$180^{\circ}$ ke arah belakang. Pada saat pemutaran sandaran punggung mencapai $180^{\circ}$, maka Kursi Tangga tersebut telah berubah fungsi menjadi sebuah tangga naik.

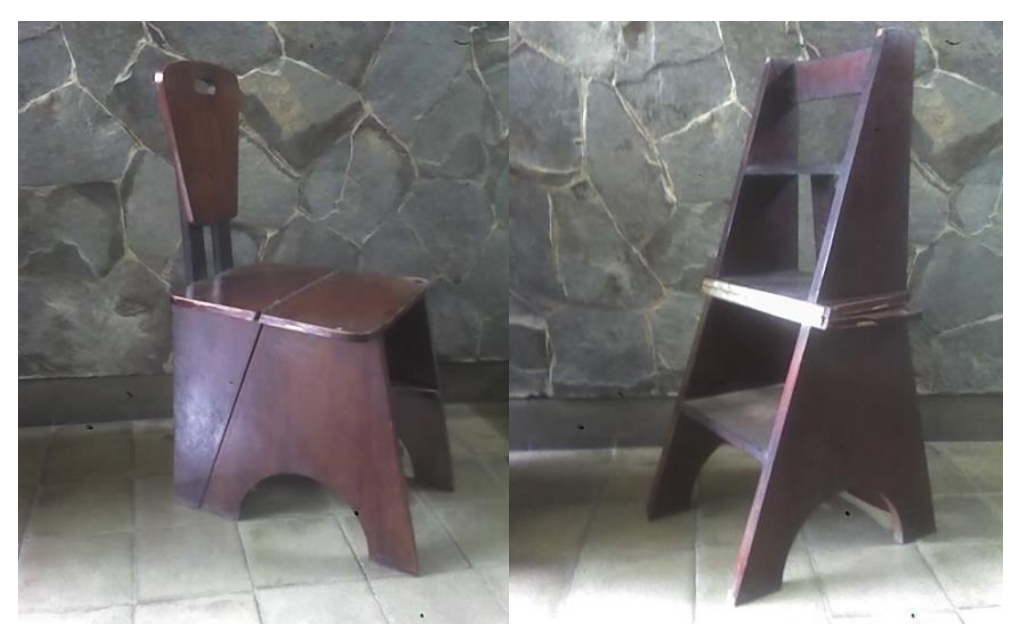

Gambar 1. Existing Kursi Tangga

Sumber: Penulis, 2019
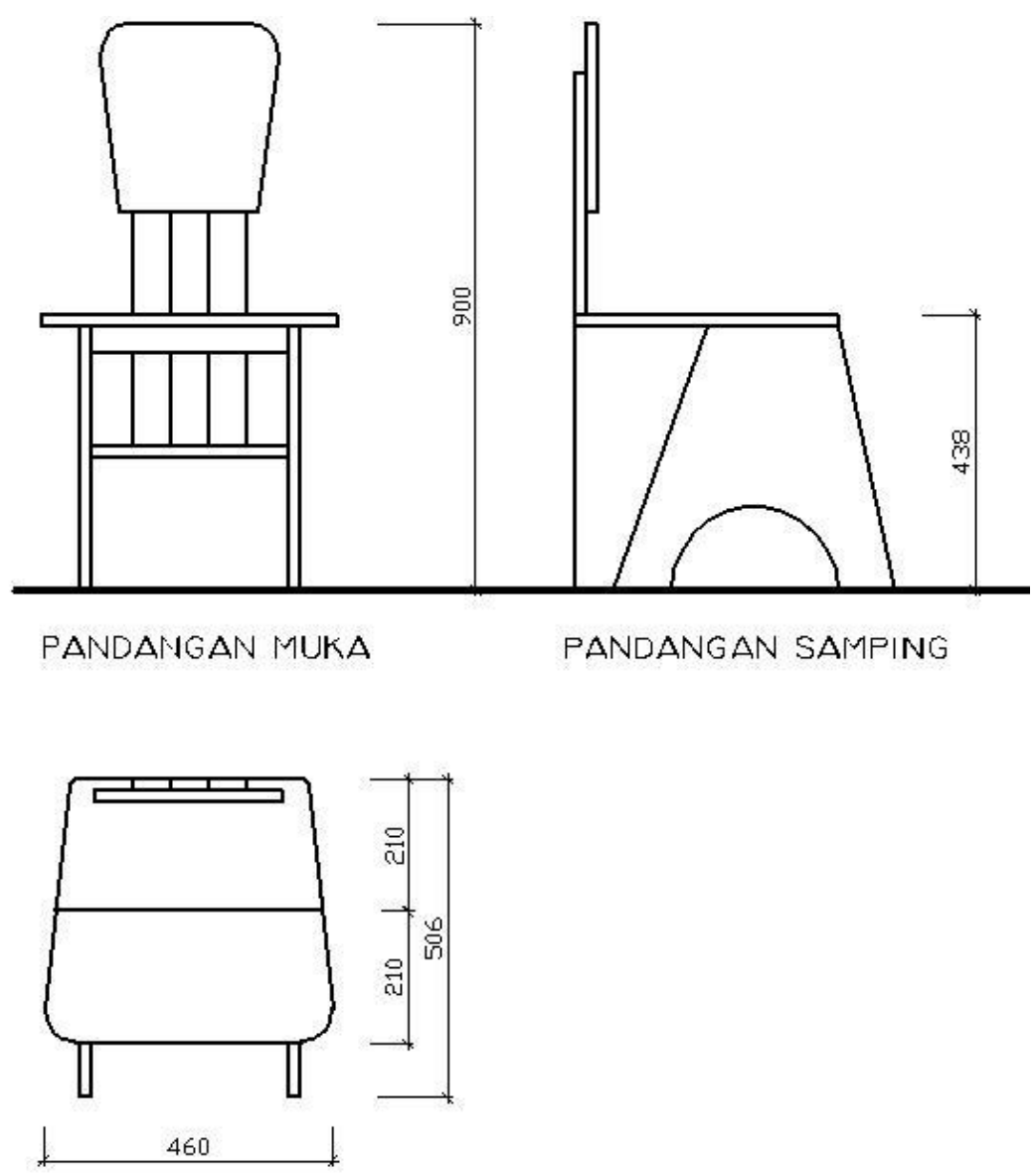

PANDANGAN ATAS

Gambar 2. Gambar Kursi Tangga

Sumber: Penulis, 2019 
Tahap selanjutnya yaitu penerapan Quality Function Deployment (QFD) dilakukan dengan langkah-langkah sebagai berikut (Cohen, 1995):

A. Mengidentifikasi kebutuhan konsumen

Mengidentifikasi kebutuhan konsumen, keinginan dan kebutuhannya adalah tahap awal dari Quality Function Deployment (QFD).

B. Membuat matriks perencanaan (Planning Matrix)

a. Tingkat kepentingan konsumen (Importance to Customer)

Penentuan tingkat kepentingan konsumen digunakan untuk mengetahui sejauh mana konsumen memberikan penilaian atau harapan dari kebutuhan konsumen yang ada.

b. Pengukuran tingkat kepuasan konsumen terhadap produk (Customer Satisfaction Performance)

Dihitung dengan Pengukuran tingkat kepuasan konsumen terhadap produk dimaksudkan untuk mengukur bagaimana tingkat kepuasan konsumen setelah pemakaian produk yang akan dianalisa. rumus :

$$
\text { Weighted Average Performance }=\frac{\sum_{t}[(\text { Number of respondents at performance value } i) i]}{(\text { Total number of respondents })}
$$

c. Nilai target (Goal)

Nilai target ini ditentukan oleh pihak perusahaan yang menunjukkan nilai target yang akan dicapai untuk tiap kebutuhan konsumen.

d. Rasio perbaikan (Improvement Ratio)

Rasio perbaikan yaitu perbandingan antara nilai target yang akan dicapai (goal) pihak perusahaan dengan tingkat kepuasan konsumen terhadap suatu produk. Dihitung dengan rumus :

$$
\text { Improvement Ratio }=\frac{\text { Goal }}{\text { Current Statisfaction Performance }}
$$

e. Titik jual (Sales Point)

Titik jual adalah kontribusi suatu kebutuhan konsumen terhadap daya jual produk. Untuk penilaian terhadap titik jual terdiri dari:

$1=$ Tidak ada titik jual

1.2 = Titik jual menengah

$1.5=$ Titik jual kuat

f. Raw Weight

Raw Weight merupakan nilai keseluruhan dari data-data yang dimasukkan dalam Planning Matrix tiap kebutuhan konsumen untuk proses perbaikan selanjutnya dalam pengembangan produk. Dihitung dengan rumus :

$$
\text { Raw Weight }=(\text { Importance to Customer }) .(\text { Improvement Ratio }) .(\text { Sales Point })
$$




\section{g. Normalized Raw Weight}

Merupakan nilai dari Raw Weight yang dibuat dalam skala antara $0-1$ atau dibuat dalam bentuk persentase. Dihitung dengan rumus sebagai berikut :

$$
\text { Normalized Raw Weight }=\frac{\text { Raw Weight }}{\sum \text { Raw Weight }}
$$

C. Penyusunan kepentingan teknik

Pada tahap ini pepeneliti mengidentifikasi kebutuhan teknik yang sesuai dengan keinginan dan kebutuhan konsumen.

D. Menentukan hubungan antara kebutuhan konsumen dengan kepentingan Teknik. Penentuan ini menunjukkan hubungan (relationship matrix) antara setiap kebutuhan konsumen dan kepentingan teknik. Pada tahap ini ada 3 macam hubungan yang terbentuk, yaitu kuat, sederhana dan lemah.

E. Penentuan prioritas

Penentuan ini menunjukkan prioritas yang akan dikembangkan lebih dulu berdasarkan kepentingan teknik.

Pada gambar 3 dapat diketahui bahwa hubungan kebutuhan berupa menggunakan bahan baku yang kuat mempunyai hubungan yang kuat (dengan nilai 9) terhadap bahan solidwood Mahoni, Multipleks biasa $18 \mathrm{~mm}$,bahan kualitas 2 dan memiliki hubungan yang sedang (dengan nilai 3) dengan proses pengeringandan pengawetan. Untuk kebutuhan konsumen yang lain dapat diketahui dengan cara pembacaan gambar yang sama. 


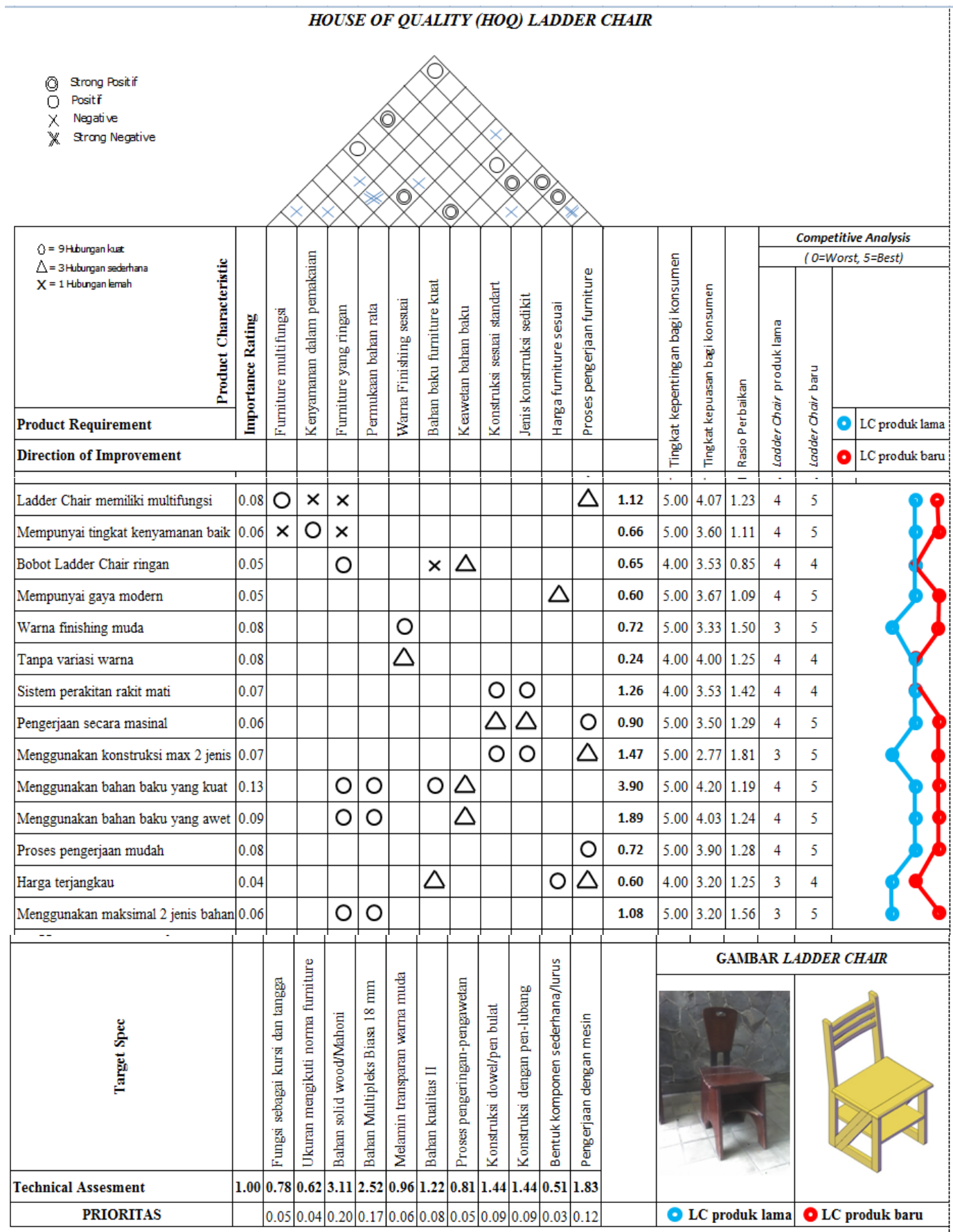

\section{Gambar 3. Matrik House Of Quality}

Sumber: Penulis, 2019

Berdasarkan hasil perhitungan yang telah dilakukan, maka dalam pengembangan produk Ladder Chair perlu memberi prioritas perhatian terutama pada variabel kebutuhan konsumen yaitu bahan baku yang kuat dengan bobot 3.90, bahan baku yang awet dengan bobot 1.89, konstruksi maksimal 2 jenis dengan bobot 1.47, Sistem perakitan rakit mati dengan bobot 1.26 dan memiliki multifungsi dengan bobot 1.12. Berdasarkan beberapa karakteristik teknis yang ada maka ditemukan beberapa karakteristuk teknis yang mempunyai bobot cukup besar yaitu bahan baku solidwood Mahoni dengan bobot 3.11, multipleks biasa $18 \mathrm{~mm}$ dengan bobot 2.52, pengerjaan dengan mesin dengan 
bobot 1.83, konstruksi dowel/pen bulat dengan bobot 1.44, konstruksi pen lubang dengan bobot 1.44. Hasil perancangan Kursi Tangga dapat dilihat pada Gambar 4.

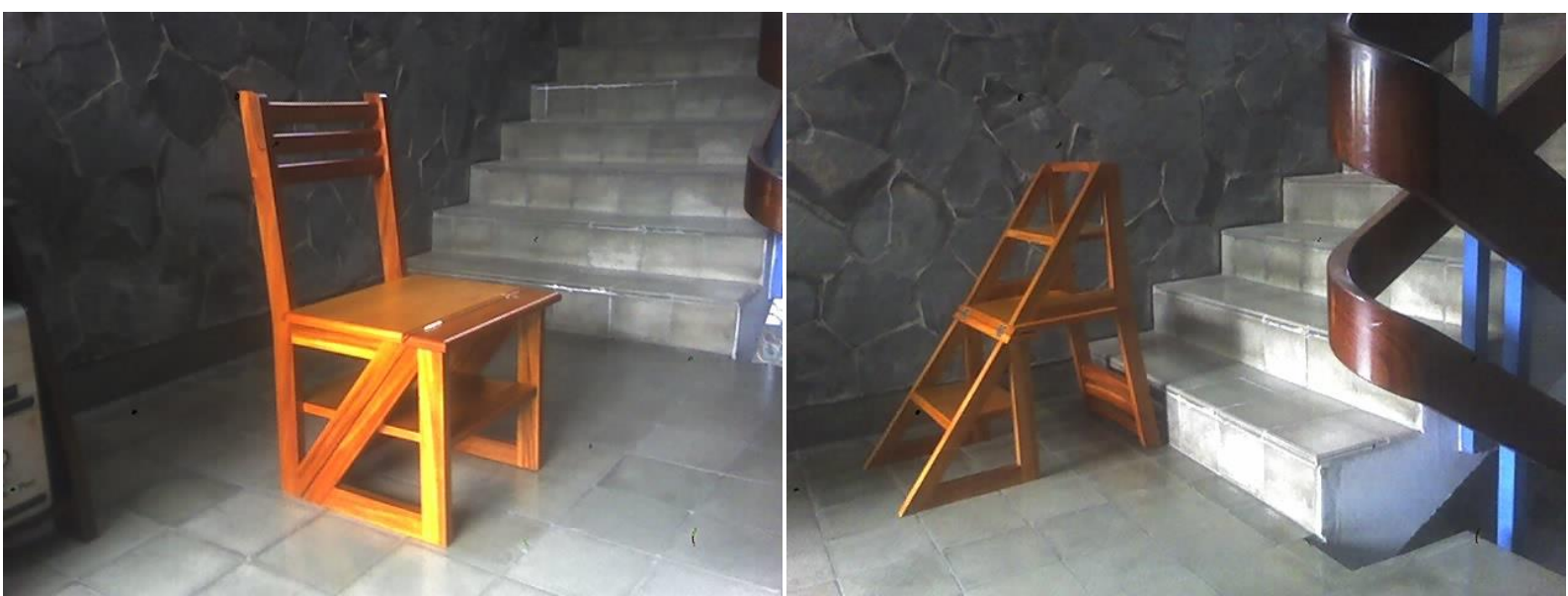

Gambar 4. Gambar Kursi Tangga yang baru

Sumber: Penulis, 2019

Kursi Tangga yang dibuat berdasarkan keinginan pelanggan kemudian diwujudkan dalam bentuk matrik House of Quality menghasilkan nilai perbandingan yang lebih baik dibandingkan dengan Kursi Tangga desain lama. Material Kursi Tangga didominasi oleh bahan dari kayu Mahoni.

\section{KESIMPULAN}

Berdasarkan data dan pembahasan yang telah dilakukan, penulis menyimpulkan penggunaan metode Quality Function Deployment terhadap proses pengembangan produk Kursi Tangga harus memperhatikan variabel kebutuhan konsumen yang memiliki bobot tinggi yaitu menggunakan bahan baku yang kuat, menggunakan bahan baku yang awet, menggunakan konstruksi maksimal 2 jenis, sistem perakitan mati, Kursi Tangga memiliki multifungsi. Dalam perancangan harus memprioritaskan karakter teknis yang memiliki bobot tinggi yaitu menggunakan bahan baku solidwood Mahoni dan multipleks biasa $18 \mathrm{~mm}$, pengerjaan dengan mesin, konstruksi dowel atau pen bulat, konstruksi pen lubang. Penelitian lanjutan dapat dilakukan kembali untuk menghasilkan produk yang lebih memenuhi keinginan pemakai dengan memperhatikan unsur-unsur pengembangan produk yang lebih luas. Penggunaan metode Quality Function Deployment sangat membantu untuk melakukan perancangan ulang produk yang sesuai dengan keinginan pemakai.

\section{Ucapan terima kasih.}

Penulis mengucapkan terima kasih kepada Direktur Akademi Teknik PIKA, Ir. Ign. Adhitjahjo LM, MM yang telah memberi kesempatan kepada penulis untuk melakukan penelitian produk Kursi Tangga ini. Ucapan terima kasih kami sampaikan pula kepada rekan-rekan dosen yang telah member masukan, saran dan support pada penelitian ini. 


\section{DAFTAR PUSTAKA}

Akmal. (2011). Desain Furniture multifungsi. Jakarta: Gramedia.

Cohen. (1995). Quality Function Development: How to make QFD Work for You. Singapore: Addison - Wesly Publishing Company.

Ginting, R. (2010). Perancangan Produk. Yogyakarta: Graha Ilmu.

Hamdani, P. (2015). Analisis Kualitas Produk Menggunakan Metode Quality Function Deployment. Bandung: Universitas Telkom.

Hartanto, T. (2014). Desain Meja Laptop Portable melalui Pendekatan Quality Function Deployment (QFD). Bandung: Thesis, Universitas Widyatama.

Nurmianto, E. (1998). Ergonomi, Konsep Dasar dan Aplikasinya. Edisi Pertama. Surabaya: Guna Widya.

Permata, E. (2017). Penerapan Quality Function Deployment (QFD) untuk Pengembangan Produk Kaos Distro. Jurusan Teknik Industri Universitas Brawijaya , 51-56.

Pheasant. (1998). Bodyspace Anthropometry, Ergonomic and Design. London - NewyorkPhiladelpia.: Taylor \& Francis.

Prabowo, R. (2016). New Product Development for Dryer Fish for SMEs Scale with Quality Function Deploiment (QFD) Method. Prosiding Seminar Internasional ICOEN 3 (pp. 327-336). Surabaya: Universitas Ciputra.

Wiliaury, M. (2015). Perancangan Mebel Multifungsi Untuk Dormitory Mahasiswa Desain. Surabaya: Universitas Kristen Petra.

Yuliarty, P. (2015). Pengembangan Desain Produk Papan Tulis Dengan Metode Quality Function Deployment (QFD). Jakarta: Universitas Mercubuana. 